Spring 2012

\title{
The Minority Stress Perspective
}

\author{
Michael P. Dentato \\ Loyola University Chicago, School of Social Work, mdentato@luc.edu
}

Follow this and additional works at: https://ecommons.luc.edu/socialwork_facpubs

Part of the Gender and Sexuality Commons, and the Social Work Commons

\section{Recommended Citation}

Dentato, M.P. (2012). The minority stress perspective. Psychology \& AIDS Exchange, 37, 12-15. American Psychological Association. Washington, D.C. (Spring Issue).

This Article is brought to you for free and open access by the Faculty Publications and Other Works by Department at Loyola eCommons. It has been accepted for inclusion in Social Work: School of Social Work Faculty Publications and Other Works by an authorized administrator of Loyola eCommons. For more information, please contact ecommons@luc.edu. cc) (†) $\Theta$

This work is licensed under a Creative Commons Attribution-Noncommercial-No Derivative Works 3.0 License. Copyright @ 2012 Michael P. Dentato 


\title{
THE MINORITY STRESS PERSPECTIVE
}

\author{
Michael P. Dentato, PhD, MSW
}

School of Social Work, Loyola University Chicago

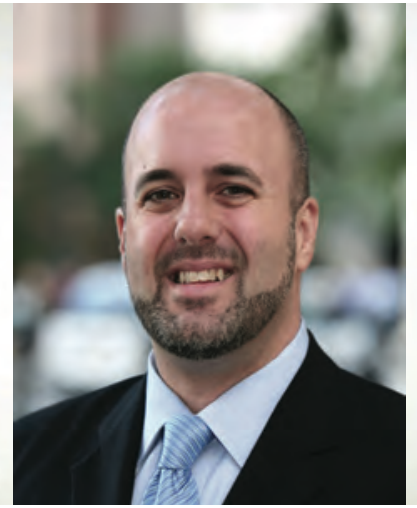

T

he minority stress perspective adds significant insight into the critical application and evaluation of theory regarding the impact of homophobia and correlates of HIV risk among gay and bisexual men and other sexual minorities. Continued understanding of the role that stigma, prejudice, heteronormativity, rejection, and internalized homophobia play in fueling HIV and substance use among gay and bisexual men is also necessary.

Researchers continue to find interest in the uniqueness of stressors related to health outcomes among minority groups (Hatzenbuehler, NolenHoeksema, \& Erickson, 2008) and whether stressors such as homophobia are associated with greater physical and mental health problems (Williams, Neighbors, \& Jackson, 2003). Typically, gay and bisexual men have greater likelihood than the general population (Cochran, Mays, \& Sullivan, 2003) for risk-taking behaviors that include polysubstance use (Kalichman \& Cain, 2004; Kashubeck-West \& Szymanski, 2008) and anonymous sex with multiple partners (Bimbi et al., 2006), and they are at greater risk for sexually transmitted infections (Halkitis, Zade, Shrem, \& Marmor, 2004) such as HIV/AIDS (Halkitis, Green,
\& Carragher, 2006; Halkitis, Green, \& Mourgues, 2005). Such risk behaviors may result from a multitude of issues associated with minority stress (Hamilton \& Mahalik, 2009; Meyer, Schwartz, $\&$ Frost, 2008); individual-level determinants (Crocker, Major, \& Steele, 1998; Jerome, Halkitis, \& Siconolfi, 2009) of behavior; and social causation associated with homophobia, stigma, and other factors (Link \& Phelan, 2006).

One of the most prominent theoretical and explanatory frameworks of sexual minority health risk is the minority stress model. The concept of minority stress stems from several social and psychological theoretical orientations and can be described as a relationship between minority and dominant values and resultant conflict with the social environment experienced by minority group members (Meyer, 1995; Mirowsky \& Ross, 1989; Pearlin, 1989). Minority stress theory proposes that sexual minority health disparities can be explained in large part by stressors induced by a hostile, homophobic culture, which often results in a lifetime of harassment, maltreatment, discrimination, and victimization (Marshal et al., 2008; Meyer, 2003) and may ultimately impact access to care.

\section{PSYCHOLOGY XaIDS EXCHANGE 12}

The Meyer (2003) minority stress modelminority stress processes in lesbian, gay, and bisexual populations-is based on factors associated with various stressors and coping mechanisms and their positive or negative impact on mental health outcomes. Significantly, many of the concepts in the model overlap, representing their interdependency (Meyer, 2003; Pearlin, 1999). The model describes stress processes, including experiences of prejudice, expectations of rejection, hiding, concealing, internalized homophobia, and ameliorative coping processes (Meyer, 2003). Stressors such as homophobia or sexual stigma that may arise from the environment require an individual to adapt but also cause significant stress, which ultimately affects physical and mental health outcomes (Dohrenwend et al., 1992).

Underlying the concept of minority stress are assumptions that stressors are unique (not experienced by nonstigmatized populations), chronic (related to social and cultural structures), and socially based (social processes, institutions, and structures) (Meyer, 2003). While this theory has been applied to other populations, including women, immigrants, the impoverished, and racial/

continued on page 13 
continued from page 12

ethnic minorities, there is still much room for additional investigation among sexual minority populations, as they do not have as rich a history in sociological investigation (Meyer et al., 2008).

A strong correlation may be drawn between (a) minority stress theory, which underscores stress processes (experience of prejudice, expectations of rejection, internalized homophobia) and ameliorative coping processes (Meyer, 2003); and (b) a greater likelihood for psychological distress and physical health problems among gay and bisexual men and other sexual minority populations. Stress theory provides a useful framework to explain and examine health disparities and the role of homophobia as a sociological paradigm that views social conditions as a cause of stress for members of disadvantaged social groups, which in turn can increase risk for HIV, among other risk factors (Aneshensel, Rutter, \& Lachenbruch, 1991; Dressler, Oths, \& Gravlee, 2005). Interestingly, there continues to be a small and growing body of research examining community and population samples that suggests a significant relationship between minority stressors and deleterious behavioral and mental health outcomes such as HIV risk among gay and bisexual men (Hatzenbuehler et al., 2008).

When gay and bisexual men apply negative attitudes toward themselves, especially with feelings associated with internalized homophobia, the psychologically injurious effects of societal level homophobia often take effect (Meyer, 1995). Such homophobia holds implications for the disproportionate impact of HIV on gay and bisexual men (Herek \& Garnets, 2007). While HIV-positive individuals are often stigmatized for their status, those who are HIV-negative live with the possibility of seroconversion, with potential for varied levels of psychological distress that may result in mental health challenges, unprotected anal intercourse, substance use, or sex with multiple partners. Such attitudes and risk behaviors increase exponentially when a member of the gay or bisexual community is also a member of a minority racial/ethnic group. Having multiple minority statuses increases the likelihood of experiencing homophobia, stigma, isolation, and rejection (Diaz, Bein, \& Ayala, 2006), along with heightened risk for sexual risk behavior or substance use.

Some studies, however, underscore the fact that individuals with multiple minority identities may actually be better equipped to cope with minority stress factors (Consolacion, Russell, \& Sue, 2004) because of a more complex self-concept and varied experiences that have involved adaptation and resilience, among other factors. Other research on ethnic minority gay and bisexual men has shown that they must confront homophobia within their own racial/ethnic community, experience alienation from the larger gay and bisexual community, and simultaneously manage their own internalized homophobia (Diaz, Ayala, Bein, Jenne, \& Marin, 2001). Such multileveled stressors can have deleterious repercussions related to sexual risk behavior and increased risk for HIV/AIDS among racial/ethnic gay and bisexual male populations.

Continued research and examination of the effect of homophobia and minority stress factors on the sexual risk behaviors of gay and bisexual men can often be complicated, as the recruitment of subjects for research studies and subsequent behavioral interventions remains limited and challenging because of difficulty accessing the community (Kanouse et al., 2005). Additionally, most research related to gay and bisexual men and their risk behavior patterns typically relies on convenience-based samples, often without heterosexual control groups. This ultimately results in ambiguity about whether gay and bisexual men experience stressors such as prejudice, rejection, and discrimination more frequently than heterosexual men and women (Mays \& Cochran, 2001).

Challenges involved in working among this vulnerable population include appropriate and effective interventions (Natale \& Moxley, 2009) and theoretical approaches for understanding risk behavior (Halkitis, Palamar, \& Mukherjee, 2007). In that regard, gay and bisexual men, along with other sexual minorities, often draw upon personal and community-level coping mechanisms and resources to develop resilience, coping, and hardiness (Meyer, 2003; Ouellette \& DiPlacido, 2001). Similarly, individuals who adopt a strong sexual minority identity may be better equipped to manage minority stressors, invalidate stereotypes, and dismiss or address perceived or actual homophobia while affirming a positive selfevaluation (Herek \& Garnets, 2007).

Clinical applications such as affirmativebased practice are effective when working with gay and bisexual men and other sexual minorities. Affirmative-based practice focuses on defining coping strategies, affirming a positive self-identity, and increasing the ability to assess the effect of homophobia and stigma on psychological functioning and health risk behavior (Browning, Reynolds, \& Dworkin, 1991). In addition, behavioral interventions administered at three levels_-individual, group, and community- 
continued from page 13

appear to effectively reduce risky sexual behaviors associated with HIV and other sexually transmitted infections (Mustanski, Newcomb, Du Bois, Garcia, \& Grov, 2011).

Other promising future directions for practice and interventions with the gay and bisexual community include Internet-based delivery and those approaches that go beyond the individual level to address a more combined approach, including structural, community, and social network factors (Mustanski et al., 2011) as well as those suggested in the recent National HIV/AIDS Strategy for the United States (Office of National AIDS Policy, 2010). The continued assessment of the efficacy of other therapeutic interventions with this population is also necessary, along with the vital role of ongoing training and clinical supervision to increase practitioner sensitivity, knowledge, and competency. Continued study of the implications of minority stress factors for gay and bisexual men may lead researchers, clinicians, and policymakers to better understand cofactors, such as homophobia, and the relationship with sexual risk behavior and increased risk for HIV/AIDS among other resultant factors.

\section{ABOUT THE AUTHOR}

Michael P. Dentato, PhD, is a clinical assistant professor at Loyola University Chicago in the School of Social Work. He received his BA and MSW from Fordham University in New York and his PhD in social work from Loyola University Chicago. Research interests include the examination of minority stress factors associated with substance use and sexual risk behavior among gay and bisexual men. In addition to teaching and research, Dr.
Dentato is a member of the Council on Sexual Orientation \& Gender Expression for the Council on Social Work Education; a faculty research affiliate at the Center for Health, Identity, Behavior and Prevention Studies at New York University's Steinhardt School of Culture, Education, and Human Development; and program consultant for the Center on Halsted in Chicago. Experience in the arena of HIV/AIDS and LGBT issues include his former role as executive director of Body Positive, New York, and the development of the Alliance for GLBTQ Youth in Miami, an organization providing a continuum of care for sexual minority youth and their families. His latest article, "The Vital Role of Social Workers in Community Partnerships for GLBTQ Youth," was published in 2010 by the Journal of Social Work With Adolescents.

\section{REFERENCES}

Aneshensel, C. S., Rutter, C. M., \& Lachenbruch, P. A. (1991) Social structure, stress and mental health: Competing conceptual and analytic models. American Sociological Review, 56, 166-178.

Bimbi, D. S., Nanin, J. E., Parsons, J. T., Vicioso, K. J., Missildine, W., \& Frost, D. (2006). Assessing gay and bisexual men's outcome expectancies for sexual risk under the influence of alcohol and drugs. Substance Use $\mathcal{E}$ Misuse, $41,643-652$.

Browning, C., Reynolds, A. L., \& Dworkin, S. H. (1991). Affirmative psychotherapy for lesbian women. Counseling Psychology, 19, 177-196.

Cochran, S. D., Mays, V. M., \& Sullivan, J. G. (2003). Prevalence of mental disorders, psychological distress, and mental health services use among lesbian, gay and bisexual adults in the United States. Journal of Consulting and Clinical Psychology, 71, 53-61.

Consolacion, T. B., Russell, S. T. \& Sue, S. (2004). Sex, race/ ethnicity, and romantic attractions: Multiple minority status adolescents and mental health. Cultural Diversity and Ethnic Minority Psychology, 10, 200-214. doi:10.1037/1099. 9809.10.3.200

\section{PSYCHOLOGY XaIDS EXCHANGE 14}

Crocker, J., Major, B., \& Steele, C. (1998). Social stigma. In D. Gilbert, S. T. Fiske, \& G. Lindzey (Eds.), The handbook of social psychology (4th ed., pp. 504-553). Boston, MA: McGraw-Hill.

Diaz, R. M., Ayala, G., Bein, E., Jenne, J., \& Marin, B. V. (2001). The impact of homophobia, poverty and racism on the mental health of Latino gay men. American Journal of Public Health, 91, 927-932.

Diaz, R. M., Bein, E., \& Ayala, G. (2006). Homophobia, poverty, and racism: Triple oppression and mental health outcomes in Latino gay men. In A. M. Omoto \& H. S. Kurtzman (Eds.), Sexual orientation and mental health (pp. 207-224). Washington, DC: American Psychological Association.

Dohrenwend, B. P., Levav, I., Shrout, P., Schwartz, S., Nahev, G., Link, B. G., . . S Stueve, A. (1992). Socioeconomic status and psychiatric disorders: The causation-selection issue. Science, 255, 946-952.

Dressler, W. W., Oths, K. S., \& Gravlee, C. C. (2005). Race and ethnicity in public health research: Models to explain health disparities. Annual Review of Anthropology, 34, 231-252.

Halkitis, P. N., Green, K. A., \& Carragher, D. J. (2006). Methamphetamine use, sexual behavior and HIV seroconversion. Journal of Gay and Lesbian Psychotherapy, 10(3/4), 95-109.

Halkitis, P. N., Green, K. A., \& Mourgues, P. (2005). Longitudinal investigation of methamphetamine use among gay and bisexual men in New York City: Findings from project bumps. Journal of Urban Health: Bulletin of the New York Academy of Medicine, 82, 18-25.

Halkitis, P. N., Palamar, J. J., \& Mukherjee, P. P. (2007). Poly-club-drug use among gay and bisexual men: A longitudinal analysis. Drug and Alcohol Dependence, 89, 153-160.

Halkitis, P. N., Zade, D. D., Shrem, M., \& Marmor, M. (2004). Beliefs about HIV non-infection and risky sexual behavior among MSM. AIDS Education and Prevention, 16, 448-458.

Hamilton, C. J., \& Mahalik, J. R. (2009). Minority stress, masculinity, and social norms predicting gay men's health risk behaviors. Journal of Counseling Psychology, 56, 132-141.

Hatzenbuehler, M. L., Nolen-Hoeksema, S., \& Erickson, S. J. (2008). Minority stress predictors of HIV risk behavior, substance use, and depressive symptoms: Results from a 
continued from page 14

prospective study of bereaved gay men. Health Psychology, $27,455-462$.

Herek, G. M., \& Garnets, L. D. (2007). Sexual orientation and mental health. Annual Review of Clinical Psychology, 3, 353 . 375. doi:10.1037/0278-6133.27.4.455

Jerome, R. C., Halkitis, P. N., \& Siconolfi, D. S. (2009). Club drug use, sexual behavior, and HIV seroconversion: A qualitative study of motivations. Substance Use $\mathcal{E}$ Misuse, 44, 303-319.

Kalichman, S. C., \& Cain, D. (2004). A prospective study of sensation seeking and alcohol use as predictors of sexual risk behaviors among men and women receiving sexually transmitted infection clinic services. Psychology of Addictive Behaviors: Journal of the Society of Psychologists in Addictive Behaviors, 18, 367-373.

Kanouse, D. E., Bluthenthal, R. N., Bogart, L., Iguchi, M. Y., Perry, S., Sand, K., \& Shoptaw, S. (2005). Recruiting drug-using men who have sex with men into behavioral interventions: A two-stage approach. Journal of Urban Health: Bulletin of the New York Academy of Medicine, 82, 109-119.

Kashubeck-West, S., \& Szymanski, D. M. (2008). Risky sexual behavior in gay and bisexual men: Internalized heterosexism, sensation seeking, and substance use. Counseling Psychologist, 36, 595-614.

Link, B. G., \& Phelan, J. C. (2006). Stigma and its public health implications. Lancet, 367, 528-529.

Marshal, M. P., Friedman, M. S., Stall, R., Kling, K. M. Miles, J., Gold, M. A., . . Morse, J. Q. (2008). Sexual orientation and adolescent substance use: A metaanalysis and methodological review. Addiction, 103, 546556.

Mays, V. M., \& Cochran, S. D., (2001). Mental health correlates of perceived discrimination among lesbian, gay, and bisexual adults in the United States. American Journal of Public Health, 91, 1869-1876.

Meyer, I. H. (1995). Minority stress and mental health in gay men. Journal of Health and Social Behavior, 36, 38-56.

Meyer, I. H. (2003). Prejudice, social stress, and mental health in lesbian, gay and bisexual populations: Conceptual issues and research evidence. Psychological Bulletin, 129, 674-697. doi:10.1037/0033-2909.129.5.674

Meyer, I. H., Schwartz, S., \& Frost, D. M. (2008). Social patterning of stress and coping: Does disadvantaged socia statuses confer more stress and fewer coping resources? Social Science $\mathcal{E}$ Medicine, 67, 368-379.

Mirowsky, J., \& Ross, C. E. (1989). Social causes of psychological distress. Hawthorne, NY: Aldine de Gruyter.

Mustanski, B. S., Newcomb, M. E., Du Bois, S. N., Garcia, S. C., \& Grov, C. (2011). HIV in young men who have sex with men: A review of epidemiology, risk and protective factors, and interventions. Journal of Sex Research, 48(2-3), 218-253.

Natale, A. P., \& Moxley, D. P. (2009). Service engagement with high-risk men who have sex with men: Challenges and implications for social work practice. Social Work in Health Care, 48, 38-56.

Office of National AIDS Policy. (2010, July). National HIV/ AIDS strategy for the United States. Retrieved from http:// www.whitehouse.gov/sites/default/files/uploads/NHAS.pdf

Ouellette, S. C., \& DiPlacido, J. (2001). Personality's role in the protection and enhancement of health: Where the research has been, where it is stuck, how it might move. In A. Baum, T. A. Revenson, \& J. E. Singer (Eds.) Handbook of health psychology (pp. 175-193). Mahwah, NJ: Erlbaum.

Pearlin, L. I. (1989). The sociological study of stress. Journal of Health and Social Behavior, 30, 241-256.

Pearlin, L. I. (1999). The stress process revisited: Reflections on concepts and their interrelationships. In C. S. Aneshensel \& J. C. Phelan (Eds.), Handbook of the sociology of mental health (pp. 395-415). New York, NY: Kluwer Academic/Plenum.

Williams, D. R., Neighbors, H. W., \& Jackson, J. S. (2003). Racial/ethnic discrimination and health: Findings from community studies. American Journal of Public Health, 93, 200-208. PSKA

\section{APA CONVENTION SYMPOSIUM}

\section{WOMEN UNDER SIEGE: DISPARITIES AND} DESPAIR

About 60 million women and girls are considered "missing" from global population statistics. These women and girls disproportionately experience sex-selective abortion, female infanticide, sexual slavery and trafficking, sexually transmitted diseases, and domestic abuse. This symposium will explore the factors contributing to disparities, such as HIV/ AIDS, violence, poverty, lack of education, old age, being of color, and disability, as well as such topics as health care, reproductive control, legal protection, cultural norms, and being female in hegemonic patriarchal societies.

Symposium presentations will include "Poverty as an Open Crusade Against Women" (Faye Reimers, PhD); "Sexual Coercion and the Sexualization of Black Girls" (Bryana H. French, PhD); "HIV/ AIDS and Women of Color" (Amanda HoustonHamilton, DMH); Violence Against Young Women With Disabilities" (M. Dolores Cimini, PhD); and "From 'Right-to-Life' to 'Duty-to-Die': A Life-Span Perspective on Violence Against Women" (Cynthia de las Fuentes, PhD).

This session is co-sponsored by the Committee on Women in Psychology (CWP), the Committee on Psychology and AIDS (COPA), the Committee on Socioeconomic Status (CSES), the Committee on Ethnic Minority Affairs (CEMA), and the Committee on Disability Issues in Psychology (CDIP). 